\title{
Penerapan Metode Preference Selection Index (PSI) Dalam Pemilihan Perguruan Tinggi Swasta Program Studi IT di Provinsi Kalimantan Timur
}

\author{
Nursobah \\ STMIK Widya Cipta Dharma, Samarinda, Indonesia \\ Email: nursobah@wicida.ac.id \\ Email Penulis Korespondensi: nursobah@wicida.ac.id
}

\begin{abstract}
Abstrak-Perguruan Tinggi merupakan wadah bagi para mahasiswa untuk menuntut ilmu setelah tamat dari sekolah menengah atas/ sekolah menengah kejuruan guna untuk melanjutkan jenjang pendidikan yang lebih tinggi, pada perguruan tinggi mahasiswa belajar sesuai jurusan yang dia minati sebagai bekal untuk mencari pekerjaan setelah tamat dari kampus tersebut. Pada pemilihan perguran tinggi perlu memilih perguruan tinggi yang mempunyai kualitas yang baik dan bisa diakui ijazah dari kampus tersebut. Jurusan Teknik Informatika merupakan salah satu jurusan yang ada di perguruan tinggi. Pemilihan jurusan juga perlu memperhatikan kualitas perguruan tinggi dan kualitas jurusan yang ada pada perguruan tinggi tersebut dianggap penting dikarenakan perguruan tinggi merupakan gerbang awal untuk menciptakan pengetahuan baru dan pengetahuan lebih untuk para peserta didiknya agar peserta didik juga menjadi seseorang yang terlatih dengan kompeten pada bidang TI, pemilihan perguruan tinggi wajib dilakukan dan banyaknya perguruan tinggi yang menawarkan jurusan yang sama kerap membuat calon peserta didik bingung. Oleh sebab itu perlu dilakukan pemilihan yang tepat dengan menggunakan metode Preference Selection Index (PSI) yang merupakan salah satu metode yang akurat dalam menyelesaikan permasalahan pengambilan keputusan. Hasil penelitian di peroleh bahwa alternatif A5 memiliki nilai terbaik dengan nilai akhir 0,67.
\end{abstract}

Kata Kunci: Sistem Pendukung Keputusan; Preference Selection Index (PSI); Prodi IT

\begin{abstract}
Higher education is a place for students to study after graduating from high school/vocational high school in order to continue their higher education level, at college students study according to the majors they are interested in as a provision to find work after graduating from campus that. In choosing a college, it is necessary to choose a university that has good quality and can be recognized by a diploma from the campus. The Department of Informatics Engineering is one of the majors in the university. The selection of majors also needs to pay attention to the quality of universities and the quality of the existing majors at these universities is considered important because universities are the starting gate to create new knowledge and more knowledge for their students so that students also become someone who is competently trained in the IT field, College selection is mandatory and the number of universities offering the same major often confuses prospective students. Therefore, it is necessary to make the right selection using the Preference Selection Index (PSI) method which is one of the accurate methods in solving decision-making problems. The results showed that alternative A5 had the best value with a final value of 0.67.
\end{abstract}

Keywords: Decision Support System; Preference Selection Index (PSI); IT Department

\section{PENDAHULUAN}

Perguruan tinggi merupakan wadah bagi para mahasiswa untuk menuntut ilmu setelah tamat dari sekolah menengah guna untuk melanjutkan jenjang pendidikan yang lebih tinggi. Suatu perguruan tinggi memiliki banyak mahasiswa dan dosen sebagai staff perngajar. Pada perguruan tinggi mahasiswa belajar sesuai jurusan yang dia minati sebagai bekal untuk mencari pekerjaan atau menciptakan lapangan pekerjaan/sebagai enterpreneur setelah tamat dari perguruan tinggi tersebut. perguruan tinggi khususnya dalam perguruan tinggi jurusan Teknologi informatika (TI) yang lebih dikenal dengan jurusan komputer merupakan jurusan yang sangat banyak diminati oleh masyarakat dunia dikarenakan program studi IT merupakan jurusan yang terus dibutuhkan dan peminat tertinggi dalam pencarian situs pekerjaan khususnya di Indonesia, karena kebutuhan terhadap terknologi tidak akan pernah ada habisnya membuat peluang terhadap masa depan lebih cerah ada pada program studi IT tersebut[1].

Tingginya peminat terhadap siswa yang akan melanjutkan pendidikan dipergutuan tinggi menyebabkan banyaknya kampus atau investor swasta berlomba-lomba membuka instansi perguruan tinggi yang memiliki jurusa TI, tetapi tidak semua perguruan tinggi yang menyediakan fasilitas yang memadai dalam memenuhi kebutuhan dalam proses ajar dan mengajar dalam bidang IT. Pada pemilihan perguran tinggi perlu memilih perguruan tinggi yang mempunyai kualitas yang baik, fasilitas lengkap, diakui oleh dinas kependidikan agar ijazah dari kampus tersebut dapat diakui oleh dunia usaha maupun dunia industri nantinya[2].

Pentingnya melakukan pemilihan terhadap perguruan tinggi yang memilik program studi IT sebagai perguruan pilihan membuat banyak calon mahasiswa maupun orang tua calon mahasiswa sulit mendapatkan informasi terkait kualitas dan kuantitas yang dimiliki masing-masing perguruan tinggi sehingga diperlukan sebuah sistem yang membantu dalam mencari informasi dan membantu pengguna dalam mendapatkan serta mengambil keputusan terhadap pilihan perguruan tingga terbaik yang sesuai dengan kapasitas dan standart diri terhadap kemampuan dalam mendapatkan pengalaman dan ilmu hebat dari perguruan tinggi yang akan dipilih nantinya, sistem tersebut biasa dikenal dengan kata sistem pendukung keputusan[3].

Sistem Pendukung Keputusan merupakan pasangan dari intelektual sumber daya manusia dengan kemampuan komputer untuk memperbaiki kualitas keputusan, yaitu sistem pendukung berbasis komputer bagi 
pembuat keputusan manajemen yang menghadapi masalah semiterstruktur. Dengan Penerapan sistem pendukung keputusan dapat membantu menyelesaikan masalah yang dihadap dan dalam penerapannya sistem ini menggunakan metode untuk melakukan analisis pengambilan suatu keputusan. Penulis menggunakan metode Preference Selection Indeks (PSI) dalam penerapan pengambilan keputusan. Metode Preference Selection Indeks (PSI) merupkan metode untuk memilih alternatif terbaik dari alternatif yang di berikan tanpa memutuskan hubungan relatif antara atribut[4].

Pada penelitian terhadahulu penggunaan metode Preference Selection Index (PSI) digunakan untuk membantu dalam menentukan pembangunan daerah terhadap daerah bagian mana saja yang akan menjadi prioritas terhadap dilakukan pembangunan daerah agar pada proses pengambilan keputusan mudah diakses dan mendapatkan hasil yang akurat sehingga metode ini sebagai alternatif dalam penyelesaian permasalahan yang baik, dan pembangunan daerah lebih merata dengan mengetahui kriteria dan hal yang menjadi pendukung terkait pembangunan prioritas daerah tersebut[5].

Penelitian lainnya penggunaan metode PSI dilakukan untuk membantu manajerial atau pemangku kepentingan terhadap pimpinan dalam menentukan karyawan yang akan diangkat menjadi suvervisor housekeeping berdasarkan sistem agar pemilihan bersifat lebih adil dan terpilih secara objectiv sehingga meningkatkan kesejahteraan dan semangat terhadap motivasi karyawan lainnya karena pemilihan berdasarkan masing-masing nilai yang dimiliki oleh kandidat calon supervisor[6].

Penelitian lainnya menunjukan metode PSI digunakan untuk menentukan perkembangan sistem terhadap pemilihan design, pada tahapan penggunaan metode PSI ini menunjukan kemajuan terhadap sistem sebuah produksi baik produksi awal hingga akhir dalam pengambilan keputusan terhadap design sering terjadi ketidak struktural dalam pengambilan keputusan yang memungkinkan kesalahan dalam pengambilan keputusan dan berdampak kepada resiko yang cukup besar dimasa yang akan mendatang, PSI digunakan untuk melihat potensi terhadap design sistem life cycle yang mendapatkan nilai yang pasti dari pengambilan keputusan [7].

Berdasarkan penjelasan di atas, maka pada penelitian ini penulis tertarik menggunakan metode Preference Selction Index (PSI) untuk melakukan Pemilihan Perguruan Tinggi Swasta Program Studi IT di Provinsi Kalimantan Timur.

\section{METODOLOGI PENELITIAN}

\subsection{Sistem Pendukung Keputusan}

Konsep sistem pendukung keputusan (SPK) dengan istilah Management Decision Sistem. Mereka mendefenisikan Sistem Pendukung Keputusan (SPK) sebagai suatu sistem yang mudah dimengerti dan mudah diterapkan dalam bentuk berbasis komputer yang dapat membantu para pengambil keputusan dalam menggunakan data dan model untuk memcahkan persoalan dan data yang tidak terstruktur sehingga membentuk sebuah data yang sudah terstruktur dalam mempermudah menetapkan sebuah pilihan dan menghasilkan informasi[8]-[11].

\subsection{Perguruan Tinggi Swasta}

Perguruan tinggi swasta merupakan perguruan tinggi yang di kelola oleh pihak swasta dan berada dalam pengawasan dinas pendidikan. Segala pembuatan gedung dan fasilitas pembelajaran di biayai oleh yayasan dari perguruan tinggi tersebut. Beda halnya dengan perguruan tinggi negeri yang berada dibawah naungan pemerintah. Penerimaan mahasiswa baru pada perguruan tinggi swasta juga berbeda dengan perguruan tinggi negeri. Mahasiswa yang kuliah di perguruan tinggi swasta mayoritas yang gagal masuk ke perguruan tinggi negeri[12].

\subsection{Metode Peference Selection Index (PSI)}

Metode Peference Selection Index (PSI) di kembangkan oleh Maniya dab Bhatt 2010 untuk memecahkan multikriteria pengambilan keputusan (MCDM). Dalam metode yang di usulkan itu tidak perlu untuk menetapkan kepentingan relatif antara atribut. Bahkan, tidak ada kebutuhan komputasi bobot atribut yang terlibat dalam pengambilan keputusan dalam metode ini. Metode ini berguna apabila ada konflik dalam menentukan kepentingan relatif antar atribut[13]-[17]. Dalam metode PSI hasilnya diperoleh dengan perhitungan minimal dan sederhana seperti apa adanya berdasarkan konsep statistik tanpa keharusan bobot atribut[2], [7], [18]-[21] Langkah-langkah prosedure PSI dapat dinyatakan sebagai berikut;

1. Tentukan masalahnya

Tentukan tujuan dan Mengidentifikasi atribut dan alternatif yang terkait Masalah pengambilan keputusan.

2. Merumuskan matriks keputusan

Langkah ini melibatkan konstruksi matriks berdasarkan semua informasi yang tersedia yang menggambarkan atribut masalah. Setiap deret keputusan di alokasikan ke satu alternatif dan setiap kolom ke satu atribut karena itu elemen Xij dari matriks keputusan X memberi atribut dalam nilai asli. Jadi, jika jumlah alternatif adalah $\mathrm{M}$ dan jumlah atributnya adalah $\mathrm{N}$, maka matriks keputusan sebagai matriks $\mathrm{N}$. M, dapat dipresentasekan sebagai berikut: 
3. Normalisasi matriks keputusan

$$
\mathrm{Xij}=\left[\begin{array}{cccc}
x 11 & x 12 & \ldots & x 1 n \\
x 21 & x 22 & \ldots & x 2 n \\
\vdots & & & \\
x m 1 & x m 2 & \ldots & x m n
\end{array}\right]
$$

Jika atribut adalah tipe menguntungkan, maka nilai yang lebih besar di inginkan yang dapat di normalisasi sebagai:

$$
N_{i j}=\frac{X_{i j}}{X_{j}^{\max }}
$$

Jika atributnya adalah tipe yang tidak menguntungkan, maka nilai yang lebih kecil adakah yang di inginkan, yang dapat di normalisasi sebagai:

$$
N_{i j}=\frac{X_{j}^{\min }}{X_{i j}}
$$

Dimana Xij adalah ukuran atribut $(i=1,2, \ldots$, dan $j=1,2, \ldots, M)$.

4. Hitung nilai mean dari data yang di normalisasi

Langkah ini, berarti nilai dari data normal dari setiap atribut di hitung dengan persamaan berikut:

$$
\mathrm{N}=\frac{1}{n} \sum_{i=1}^{n} N_{i j}
$$

5. Hitung nilai variasi preferensi

Pada langkah ini sebuah nilai variasi preferensi antara nilai setiap atribut dihitung dengan menggunakan persamaan berikut:

$$
\phi_{j}=\sum_{i=1}^{n}\left[N_{11}-N\right]^{2}
$$

6. Tentukan penyimpangan dalam nilai preferensi

7. Tentukan kriteria bobotnya

$$
\Omega_{j}=1-\phi_{j}
$$

$$
\omega_{j}=\frac{\Omega_{j}}{\sum_{j=1}^{m} \Omega_{j}}
$$

Nilai total keseluruhan kriteria bobotnya semua atributnya harus satu, misalnya $\sum_{j=1}^{m} \Omega_{j}=1$.

8. $\quad$ Hitung PSI $\left(\theta_{i}\right)$

Sekarang, hitunglah pemilihan preferensi indeks $\left(\theta_{i}\right)$ untuk semua alternatif menggunakan persamaan berikut:

$$
\theta_{i}=\sum_{j=1}^{m} X_{i j} \omega_{j}
$$

9. Pilih alternatif yang sesuai untuk aplikasi yang di berikan

10. Akhirnya, masing-masing alternatif digolongkan menurut descending atau menaik utuk memudahkan manajerial interprestasi hasilnya. Alternatif yang paling tinggi indeks pilihan preferensi akan di golongkan terlebih dahulu dan seterusnya.

\section{HASIL DAN PEMBAHASAN}

Pada pemilihan perguran tinggi perlu memilih perguruan tinggi yang mempunyai kualitas yang baik dan bisa di akui ijazah dari kampus tersebut. Jurusan Teknik Informatika merupakan salah satu jurusan yang ada di perguruan tinggi. Pemilihan jurusan juga perlu memperhatikan kualitas perguruan tinggi dan kualitas jurusan yang ada pada perguruan tinggi tersebut.

Setiap calon mahasiswa memiliki strategi pemilihan jurusan Teknik Informatika yang berbeda-beda. Setelah tamat dari sekolah menengah rata-rata siswa yang mau memilih perguruan tinggi swasta dengan jurusan Teknik Informatika merasa kebingungan. Hal ini disebabkan cara pemilihan perguruan tinggi swasta yang tidak akurat. Calon mahasiswa sering terbawa arus oleh suatu brosure, mahasiwa yang kuliah pada suatu perguruan tinggi swasta tersebut, dan bisa juga karena dekat dengan tempat tinggalnya. Jika tidak di cermati dan di persiapkan sebaik-baiknya maka akan menimbulkan penyesalan setelah masa perkuliahan. Untuk mengatasi hal tersebut maka di butuhkan suatu Sistem Pendukung Keputusan.

\subsection{Penerapan Alternatif dan Kriteria}

Dalam pemilhan perguruan tinggi swasta program studi IT, sesuai dengan metode preference selection index (PSI) yang merupakan penyelesaian masalah yang di perlukan adanya kriteria-kriteria dan bobot untuk melakukan proses perhitunannya sehingga akan di dapat alternatif terbaik, dalam penelitian ini alternatif yang dimaksud penulis adalah penyeleksian perguruan tinggi swasta program studi IT yang akan di pilih calon mahasiswa yang ingin melanjutkan pendidikannya.

Metode Preference Selection Index (PSI) akan menghasilkan bobot tersendiri dalam tahapan penyelesaian masalahnya sehingga penelitian ini lebih akurat pada setiap tahap penyelesaiannya. Pada tabel 1 terdapat 6 (enam) kriteria yang memiliki pengaruh dalam pemilihan PTS Program Studi IT. 
ISSN 2614-5278 (media cetak), ISSN 2548-8368 (media online)

Available Online at https://ejurnal.stmik-budidarma.ac.id/index.php/mib DOI 10.30865/mib.v5i3.3081

Tabel 1. Data Kriteria

\begin{tabular}{clc}
\hline Kriteria & \multicolumn{1}{c}{ Kriteria } & Jenis \\
\hline C1 & Jumlah Prodi IT & Benefit \\
C2 & Total Jumlah Mahasiswa IT & Benefit \\
C3 & Rasio 1 Dosen per Mahasiswa & Cost \\
C4 & Akreditasi PT & Benefit \\
C5 & Rangking Sinta PT (3 tahun) & Cost \\
C6 & Jumlah Akreditasi Prodi IT & Benefit \\
\hline
\end{tabular}

Berikut pada tabel 2 merupakan data dari tiap-tiap alternatif pada setiap kriteria.

Tabel 2. Rating Kecocokan Dari Setiap Alternatif Pada Setiap Kriteria

\begin{tabular}{lcccccc}
\hline \multicolumn{1}{c}{ Alternatif } & C1 & C2 & C3 & C4 & C5 & C6 \\
\hline STMIK Widya Cipta Dharma(A1) & 3 & 1777 & 23 & B & 700 & 3 \\
STMIK Samarinda (A2) & 2 & 85 & 8.5 & C & 5045 & 1 \\
Universitas Nahdlatul Ulama Kalimantan Timur(A3) & 1 & 56 & 8 & - & 2142 & 1 \\
Universitas Muhammadiyah Kalimantan Timur (A4) & 1 & 318 & 16.7 & B & 237 & 1 \\
Universitas Mulia (A5) & 6 & 2405 & 27.3 & C & 1053 & 4 \\
\hline
\end{tabular}

Sumber: BAN PT, Forlap Kemendikbud, dan SINTA (2021)

Pada tabel 2 di atas terdapat data yang memiliki nilai linguistik, yaitu pada kriteria 4, dimana terdapat peringkat akreditasi. Data ini perlu di lakukan pembobotan sederhana berdasarkan tabel 3 berikut ini:

Tabel 3. Rating Kecocokan Dari Setiap Alternatif Pada Setiap Kriteria

\begin{tabular}{clc}
\hline \multicolumn{1}{c}{ Kriteria } & \multicolumn{1}{c}{ Nilai } & Bobot \\
\hline & A/Unggul & 4 \\
Akreditasi PT(C4) & B/Baik Sekali & 3 \\
& C/Baik & 2 \\
& Tidak Terakreditasi & 1 \\
\hline
\end{tabular}

Dari hasil pembobotan, maka diperoleh rating kecocokan yang terlihat pada tabel 4, berikut ini.

Tabel 4. Rating Kecocokan Dari Setiap Alternatif Pada Setiap Kriteria

\begin{tabular}{ccccccc}
\hline Alternatif & C1 & C2 & C3 & C4 & C5 & C6 \\
\hline A1 & 3 & 1777 & 23 & 3 & 700 & 3 \\
A2 & 2 & 85 & 8.5 & 2 & 5045 & 1 \\
A3 & 1 & 56 & 8 & 1 & 2142 & 1 \\
A4 & 1 & 318 & 16.7 & 3 & 237 & 1 \\
A5 & 6 & 2405 & 27.3 & 2 & 1053 & 4 \\
\hline
\end{tabular}

\subsection{Penerapan Metode Preference Selection Index (PSI)}

Setelah data rating kecocokan di peroleh maka pada bagian ini dilakukan penerapan pengambilan keputusan dengan menerapkan metode PSI. Berikut tahapan proses yang dilakukan:

1. Merumuskan Matriks Keputusan (1)

$$
\mathrm{Xij}=\mid \begin{array}{cccccc}
3 & 1777 & 23 & 3 & 700 & 3 \\
2 & 85 & 8.5 & 2 & 5045 & 1 \\
1 & 56 & 8 & 1 & 2142 & 1 \\
1 & 318 & 16.7 & 3 & 237 & 1 \\
6 & 2405 & 27.3 & 2 & 1053 & 4
\end{array}
$$

2. Normalisasi Matriks Keputusan (2)

$$
\begin{aligned}
& X_{j 1}^{\text {max }}=[6,2405,27.3,3,5045,4] \\
& X_{j 1}^{\text {min }}=[1,56,8,1,237,1] \\
& X_{j 1}^{\text {max }}=100 \\
& N_{11}=\frac{X_{11}}{X_{j 1}^{\max }}=\frac{3}{6}=0,85 \\
& N_{21}=\frac{X_{21}}{X_{j 1}^{\text {max }}}=\frac{2}{6}=0,65 \\
& N_{31}=\frac{X_{31}}{X_{j 1}^{\max }}=\frac{1}{6}=1
\end{aligned}
$$


JURNAL MEDIA INFORMATIKA BUDIDARMA

Volume 5, Nomor 3, Juli 2021, Page 1045-1051

ISSN 2614-5278 (media cetak), ISSN 2548-8368 (media online)

Available Online at https://ejurnal.stmik-budidarma.ac.id/index.php/mib DOI 10.30865/mib.v5i3.3081

$$
\begin{aligned}
& N_{41}=\frac{X_{41}}{X_{j 1}^{\text {max }}}=\frac{1}{6}=0,65 \\
& N_{51}=\frac{X_{51}}{X_{j 1}^{\text {max }}}=\frac{1}{6}=0,8
\end{aligned}
$$

Dari perhitungan di atas diperoleh maatriks $N_{i j}$

$$
\mathrm{N}_{\mathrm{ij}}\left|\begin{array}{rrrrrr}
0,5 & 0,738877 & 0,347826087 & 1 & 0,338571 & 0,75 \\
0,333333 & 0,035343 & 0,941176471 & 0,666667 & 0,046977 & 0,25 \\
0,166667 & 0,023285 & 1 & 0,333333 & 0,110644 & 0,25 \\
0,166667 & 0,132225 & 0,479041916 & 1 & 1 & 0,25 \\
1 & 1 & 0,293040293 & 0,666667 & 0,225071 & 1
\end{array}\right|
$$

Melakukan penjumlahan matriks $N_{i j}$ setiap atribut $\sum_{i=n}^{n} N_{i j}=N_{11}+N_{21}+N_{31}+N_{41}+\ldots+N_{m n}$

$\sum_{i=1}^{n} N_{j 1}=N_{11}+N_{21}+N_{31}+N_{41}+N_{51}$

$$
=0,5+0,333333+0,166667+0,166667+1
$$

$=2,166667$

$\sum_{i=2}^{n} N_{j 2}=N_{12}+N_{22}+N_{32}+N_{42}+N_{52}$

$=0,738877+0,035343+0,023285+0,023285+1$

$=1,92973$

$\sum_{i=3}^{n} N_{j 3}=N_{13}+N_{23}+N_{33}+N_{43}+N_{53}$

$=0,347826087+0,941176471+1+0,479041916+0,293040293$

$=3,061084$

$\sum_{i=4}^{n} N_{j 4}=N_{14}+N_{24}+N_{34}+N_{44}+N_{54}$

$=1+0,666667+0,333333+1+0,666667$

$=3,66667$

$\sum_{i=5}^{n} N_{j 5}=N_{15}+N_{25}+N_{35}+N_{45}+N_{55}$

$=0,338571+0,046977+0,110644+1+0,225071$

$=1,721264$

$\sum_{i=6}^{n} N_{j 6}=N_{16}+N_{26}+N_{36}+N_{46}+N_{56}$

$=0,338571+0,046977+0,110644+1+0,225071$

$=1,721264$

Hasil yang diperoleh dari perhitungan di atas adalah sebagai berikut:

$$
\sum_{i=1}^{n} N_{i j}=\left|\begin{array}{llllll}
2,1666667 & 1,9297297 & 3,061084767 & 3,6666667 & 1,7212641 & 2,5
\end{array}\right|
$$

3. Menghitung nilai mean dari data yang telah di normalisasi (4)

$\mathrm{N}=\frac{1}{n} \sum_{i=1}^{n} N_{j 1}=\frac{1}{6} 2,1666667=0,8142$

$\mathrm{N}=\frac{1}{n} \sum_{i=1}^{n} N_{j 2}=\frac{1}{6} 1,9297297=0,0893$

$\mathrm{N}=\frac{1}{n} \sum_{i=1}^{n} N_{j 3}=\frac{1}{6} 3,061084767=0,8571$

$\mathrm{N}=\frac{1}{n} \sum_{i=1}^{n} N_{j 4}=\frac{1}{6} 3,6666667=0,8888$

$\mathrm{N}=\frac{1}{n} \sum_{i=1}^{n} N_{j 4}=\frac{1}{6} 1,7212641=0,8888$

$\mathrm{N}=\frac{1}{n} \sum_{i=1}^{n} N_{j 4}=\frac{1}{6} 2,5=0,8888$

Hasil perhitungan di atas mendapatkan nilai mean yaitu:

$N=\left|\begin{array}{llllll}0,361111 & 0,321622 & 0,510180794 & 0,611111 & 0,286877 & 0,416667\end{array}\right|$

4. Menghitung nilai variasi preferensi (5)

$\phi_{j 11}=\sum_{i=1}^{n}\left[N_{11}-N\right]^{2}=\sum_{i=1}^{n}(0,5-0,361111)^{2}=0,0192901$

$\phi_{j 21}=\sum_{i=1}^{n}\left[N_{21}-N\right]^{2}=\sum_{i=1}^{n}(0,333333-0,361111)^{2}=0,0007734$

$\phi_{j 31}=\sum_{i=1}^{n}\left[N_{31}-N\right]^{2}=\sum_{i=1}^{n}(0,166667-0,361111)^{2}=0,0378084$

$\left.\phi_{j 41}=\sum_{i=1}^{n}\left[N_{41}-N\right]^{2}=\sum_{i=1}^{n} 0,166667-0,361111\right)^{2}=0,0378084$

$\left.\phi_{j 51}=\sum_{i=1}^{n}\left[N_{51}-N\right]^{2}=\sum_{i=1}^{n} 1-0,361111\right)^{2}=0,408179$

Hasil perhitungan pangkat pada matriks $\phi_{j}$

$\phi_{j 11}\left|\begin{array}{rrrrrr}0,0192902 & 0,174102 & 0,0263591 & 0,1512347 & 0,0026723 & 0,1111109 \\ 0,0007716 & 0,0819556 & 0,1857573 & 0,0030864 & 0,0575519 & 0,0277779 \\ 0,0378086 & 0,0890051 & 0,2399229 & 0,0771604 & 0,031058 & 0,0277779 \\ 0,0378086 & 0,0358714 & 0,0009696 & 0,1512347 & 0,5085444 & 0,0277779\end{array}\right|$

Nursobah, Copyright @2021, MIB, Page 1049 
ISSN 2614-5278 (media cetak), ISSN 2548-8368 (media online)

Available Online at https://ejurnal.stmik-budidarma.ac.id/index.php/mib

DOI 10.30865/mib.v5i3.3081

$$
\begin{array}{llllll}
0,4081792 & 0,4601967 & 0,04715 & 0,0030864 & 0,00382 & 0,3402774
\end{array} \mid
$$

Kemudian menjumlahkan hasil nilai pangkat pada matriks $\phi_{j}$

Hasil matriks $\phi_{j}$

$$
\Sigma \phi_{j}=\left|\begin{array}{llllll}
0,503858 & 0,841131 & 0,500159 & 0,385803 & 0,603647 & 0,534722
\end{array}\right|
$$

Menentukan penyimpangan dalam nilai preferensi (3.6)

$\Omega_{j}=1-0,503858=0,496142$

$\Omega_{j}=1-0,841131=0,158869$

$\Omega_{j}=1-0,841131=0,499814$

$\Omega_{j}=1-0,385803=0,614197$

$\Omega_{j}=1-0,603647=0,396353$

$\Omega_{j}=1-0,534722=0,465278$

Hasil perhitungan nilai preferensi menghasilkan matriks $\Omega_{j}$

$\Omega_{j}=\left[\begin{array}{llllll}0,496142 & 0,158869 & 0,499814 & 0,614197 & 0,396353 & 0,396353\end{array}\right]$

Menghitung nilai total keseluruhan pada matriks $\Omega_{j}$

$\sum \Omega_{j}=2,630681$

5. Tentukan kriteria bobotnya (7)

Masing-masing kriteria ilia preferensi dibagi degan total keseluruhan nilai preferensi yang sudah dijumlahkan sehingga hasil perhitungan nilai keseluruhan kriteria bobotnya $\omega_{j}$

$$
\omega_{j}=\left|\begin{array}{llllll}
0,1885983 & 0,0603909 & 0,1900045 & 0,2334747 & 0,1506657 & 0,176866
\end{array}\right|
$$

6. Hitung PSI

Pada tahapan ini setiap nilai alternatif yang sudah dilakukan normalisasi dikalikan dengan hasil akhir bobot kriteria sehigga hasil sebagai berikut ini:

Hasil perhitungan perkalian pada matriks $\theta_{i}$

$\theta_{i}=\left|\begin{array}{rrrrrr}0,0942992 & 0,0446208 & 0,0660885 & 0,2334747 & 0,0510111 & 0,1326495 \\ 0,0628661 & 0,0021344 & 0,1788278 & 0,1556498 & 0,0070779 & 0,0442165 \\ 0,0314331 & 0,0014062 & 0,1900045 & 0,0778249 & 0,0166703 & 0,0442165 \\ 0,0314331 & 0,007985 & 0,0910201 & 0,2334747 & 0,1506657 & 0,0442165 \\ 0,1885983 & 0,06039 & 0,055679 & 0,1556498 & 0,0339105 & 0,176866\end{array}\right|$

Penjumlahan pada perkalian matriks $\theta_{i}$ di atas dilakuka denga menjumlahkan nilai keseluruhan alternatif sehingga didapatkan hasil akhir pada matriks $\theta_{i}$ sebagai berikut ini

$$
\theta_{i}=\left|\begin{array}{l}
0,6221438 \\
0,4507724 \\
0,3615554 \\
0,5587951 \\
0,6710936
\end{array}\right|
$$

7. Hasil akhir matriks digolongkan menurut descending atau menaik untuk memudahkan manajerial interpretasi hasilnya.

Tabel 5. Nilai untuk masing-masing alternatif

\begin{tabular}{lcc}
\hline \multicolumn{1}{c}{ Perguruan Tinggi Swasta } & Nilai & Rank \\
\hline STMIK Widya Cipta Dharma(A1) & 0,6221438 & 2 \\
STMIK Samarinda (A2) & 0,4507724 & 4 \\
Universitas Nahdlatul Ulama Kalimantan Timur (A3) & 0,3615554 & 5 \\
Universitas Muhammadiyah Kalimantan Timur (A4) & 0,5587951 & 3 \\
Universitas Mulia (A5) & 0,6710936 & 1 \\
\hline
\end{tabular}

Pada tabel 5 terlihat nilai tertinggi ada pada Universitas Mulia sehingga alternatif yang menjadi pilihan terbaik dari alternatif lainnya.

\section{KESIMPULAN}

Beberapa kesimpulan yang bisa penulis hasilkan berkaitan dengan penelitian yang dilakukan, diantaranya dengan adanya Sistem Pendukung Keputusan pada pemilihan perguruan tinggi swasta program studi IT di Kalimantan Timur, akan membantu para tamatan sekolah menengah yang ingin melanjutkan tingkat pendidikannya karena dirasakan dapat meningkatkan efektivitas dan efisiensi dalam pengambilan keputusan. Model yang digunakan untuk suatu keputusan yaitu Preferensi Selection Index (PSI) karena model ini lebih alternatif terbaik dari beberapa 
alternatif dan menggunakan lebih dari satu kriteria. Hasil yang diberikan pada Sistem Pendukung Keputusan ini akan lebih mengefisiensikan waktu dalam mendapatkan informasi terhadap pemilihan perguruan tinggi swasta program studi IT di provinsi Kalimantan Timur.

\section{REFERENCES}

[1] R. R. et all Aliyyah, "Bidikmisi: Analisis Pelaksanaan Program Beasiswa Pendidikan Tinggi," Alignment J. Adm. Educ. Manag., vol. 3, no. 1, pp. 37-54, 2020.

[2] Y. Ali and Aprina, "Penerapan Metode Preference Selection Index ( PSI ) Dalam Pemberian Dana BOS Pada Siswa Kurang Mampu,” Semin. Nas. Teknol. Komput. Sains, no. 1, pp. 590-597, 2019.

[3] T. Mardiana and S. S. Tanjung, "Sistem Pendukung Keputusan Pemilihan Perguruan Tinggi Swasta Menggunakan Topsis," J. Ris. Inform., vol. 1, no. 2, pp. 25-34, 2019.

[4] M. Mesran, N. Huda, S. N. Hutagalung, K. Khasanah, and A. Iskandar, "SISTEM PENDUKUNG KEPUTUSAN PEMILIHAN SUPERVISOR TERBAIK PADA BAGIAN PERENCANAAN PT. PLN (PERSERO) AREA MEDAN MENERAPKAN PREFERENCE SELECTION INDEX,” KOMIK (Konferensi Nas. Teknol. Inf. dan Komputer), vol. 2, no. 1 , Oct. 2018.

[5] M. K. Siahaan, M. Mesran, S. A. Hutabarat, and J. Afriany, "Sistem Pendukung Keputusan Penentuan Prioritas Pembangunan Daerah Menerapkan Metode Preference Selection Index (Psi)," KOMIK (Konferensi Nas. Teknol. Inf. dan Komputer), vol. 2, no. 1, pp. 370-375, 2018.

[6] R. Panggabean and N. A. Hasibuan, "Penerapan Preference Selection Index ( PSI ) Dalam Sistem Pendukung Keputusan Pengangkatan Supervisor Housekeeping,” Rekayasa Tek. Inform. dan Inf., vol. 1, no. 2, pp. 85-93, 2020.

[7] R. Attri and S. Grover, "Application of preference selection index method for decision making over the design stage of production system life cycle," J. King Saud Univ. - Eng. Sci., vol. 27, no. 2, pp. 207-216, 2015.

[8] T. Limbong et al., Sistem Pendukung Keputusan: Metode \& Implementasi. Medan: Yayasan Kita Menulis, 2020.

[9] D. Nofriansyah, Multi Criteria Decision Making. Yogyakarta: Deepublish, 2017.

[10] D. Nofriansyah and S. Defit, Multi Criteria Decision Making (MCDM) pada Sistem Pendukung Keputusan. 2018.

[11] Efraim Turban and Jay E. Aronson, Decision Support System and Intelligent Systems. 2001.

[12] A. P. Utomo, "Pemodelan Arsitektur Enterprise Sistem Informasi Akademik Pada Perguruan Tinggi Menggunakan Enterprise Architecture Planning," Simetris J. Tek. Mesin, Elektro dan Ilmu Komput., vol. 5, no. 1, p. 33, 2014.

[13] S. H. Sahir et al., "The Preference Selection Index method in determining the location of used laptop marketing," Int. J. Eng. Technol., vol. 7, no. 3.4 Special Issue 4, 2018.

[14] M. Madić, J. Antucheviciene, M. Radovanović, and D. Petković, "Determination of laser cutting process conditions using the preference selection index method," Opt. Laser Technol., vol. 89, no. October 2016, pp. 214-220, 2017.

[15] M. Kumar and A. Kumar, "Application of preference selection index method in performance based ranking of ceramic particulate (SiO2/SiC) reinforced AA2024 composite materials," Mater. Today Proc., vol. 27, no. xxxx, pp. 2667$2672,2019$.

[16] M. Rizki and G. Ginting, "Penerapan Metode Preference Selection Index Dalam Pemilihan Teller Terbaik," Build. Informatics, Technol. Sci., vol. 2, no. 2, pp. 127-134, 2020.

[17] B. Vahdani, S. M. Mousavi, and S. Ebrahimnejad, "Soft computing-based preference selection index method for human resource management," J. Intell. Fuzzy Syst., vol. 26, no. 1, pp. 393-403, 2014.

[18] F. Syahputra, M. Mesran, I. Lubis, and A. P. Windarto, "Sistem Pendukung Keputusan Pemilihan Guru Berprestasi Kota Medan Menerapkan Metode Preferences Selection Index (Studi Kasus : Dinas Pendidikan Kota Medan)," KOMIK (Konferensi Nas. Teknol. Inf. dan Komputer), vol. 2, no. 1, pp. 147-155, 2018.

[19] M. Mesran, N. Huda, S. N. Hutagalung, K. Khasanah, and A. Iskandar, "Sistem Pendukung Keputusan Pemilihan Supervisor Terbaik Pada Bagian Perencanaan Pt. Pln (Persero) Area Medan Menerapkan Preference Selection Index," KOMIK (Konferensi Nas. Teknol. Inf. dan Komputer), vol. 2, no. 1, pp. 403-409, 2018.

[20] H. C. P. Siti Aisyah, "Sistem Pendukung Keputusan Pemilihan Oli Sepeda Motor Matic Terbaik Menerapkan Metode Preference Selection Index."

[21] Mesran, K. Tampubolon, R. D. Sianturi, F. T. Waruwu, and A. P. U. Siahaan, "Determination of Education Scholarship Recipients Using Preference Selection Index,” Int. J. Sci. Res. Sci. Technol., vol. 3, no. 6, pp. 230-234, 2017. 